\title{
Potential role of rivaroxaban in patients with acute coronary syndrome
}

This article was published in the following Dove Press journal:

Drug Design, Development and Therapy

21 November 2012

Number of times this article has been viewed

\section{David H Fitchett}

Division of Cardiology, Department of Medicine, St Michael's Hospital, University of Toronto, Toronto, Ontario, Canada

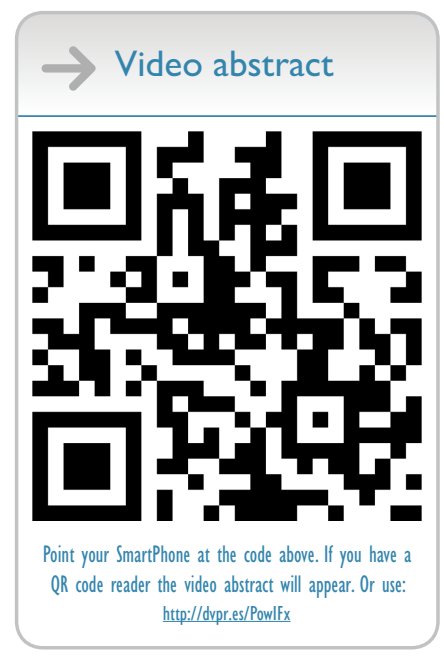

Correspondence: David H Fitchett Division of Cardiology, Room 6036, St Michael's Hospital, 30 Bond St, Toronto, Ontario M5B IW8, Canada Tel + I 4168645627

Email fitchettd@smh.ca
Abstract: Patients with acute coronary syndrome (ACS) continue to be at risk for recurrent ischemic events, despite an early invasive strategy and the use of dual antiplatelet therapy. The anticoagulant pathway remains activated for a prolonged period after ACS and, consequently, has been a target for treatment. Early studies with warfarin indicated its benefit, but the risk of bleeding and the complexities of warfarin anticoagulation resulted in little use of this strategy. Rivaroxaban, apixaban, and dabigatran are new specific inhibitors of anticoagulant factors (Xa or IIa) currently available for the prevention of thrombosis and/or thromboembolism. Thus far, studies with dabigatran and apixaban in ACS have shown no clinical benefit and bleeding has been increased. The ATLAS ACS 2-TIMI 51 trial observed the impact of rivaroxaban $2.5 \mathrm{mg}$ and $5 \mathrm{mg}$ twice daily in patients with recent ACS receiving current management (both early invasive strategy and dual antiplatelet therapy with aspirin and clopidogrel) over a follow-up period of over 1 year. Rivaroxaban $2.5 \mathrm{mg}$ twice daily reduced cardiovascular death, myocardial infarction, or stroke by $16 \%$, and both cardiovascular and all-cause mortality by approximately $20 \%$. Although major bleeding increased from $0.6 \%$ to $2.1 \%$ and intracranial hemorrhage from $0.2 \%$ to $0.6 \%$, there was no increase in fatal bleeding. The role of rivaroxaban in the management of ACS is discussed in this review. The reduction in mortality is the main finding that could lead to the use of rivaroxaban in the management of ACS in high-risk individuals with a low bleeding risk.

Keywords: cardiovascular death, myocardial infarction, stroke, anticoagulation, bleeding risk

\section{Introduction}

Recurrent ischemic events due to atherothrombosis occur commonly after acute coronary syndrome (ACS) despite dual antiplatelet therapy and an early invasive strategy in high-risk patients. In the CURE trial, ${ }^{1}$ during the 12 months after the index event, myocardial infarction (MI), stroke, and cardiovascular (CV) death occurred in $9.3 \%$ of patients receiving dual antiplatelet therapy with acetylsalicylic acid (ASA) and clopidogrel. In the recent PLATO trial, ${ }^{2}$ using a more effective antiplatelet agent, ticagrelor, the same combined end point occurred in $9.8 \%$ of patients over the 12 months following the MI. As the coagulation system is activated and excess thrombin generation persists for at least 6 months beyond the acute phase of ACS, ${ }^{3}$ inhibition of the coagulation pathway is a potential target to reduce the residual risk of recurrent ischemic events.

In the early management of ACS, short-term administration of anticoagulation with heparin or low molecular weight heparins, ${ }^{4}$ fondaparinux, ${ }^{5}$ and bivalirudin ${ }^{6}$ has been shown to reduce ischemic events when added to antiplatelet therapy. 
More prolonged administration of the low molecular weight heparin dalteparin reduced ischemic events over the first 45 days of treatment but not when used for a longer duration. ${ }^{7}$ Until recently, the only oral anticoagulant available was warfarin, which has been studied in several clinical trials of patients with ACS.

\section{Warfarin and ACS}

Studies of warfarin in patients with recent ACS were published between 1990 and 2002. The results of a meta-analysis of ten warfarin trials in ACS were largely determined by the WARIS ${ }^{8}$ and the OASIS ${ }^{9}$ studies. The meta-analysis ${ }^{10}$ (Figure 1) showed that warfarin added to ASA reduced ischemic events compared with ASA alone (MI relative risk [RR] 0.56 [95\% confidence interval (CI) 0.48-0.69]), ischemic stroke (RR 0.46 [95\% CI $0.27-0.77]$ ), yet mortality was not different in the two treatment groups. Bleeding was increased substantially in the patients receiving warfarin (RR 2.5 [95\% CI 1.7-3.7]). Due to the increased risk of hemorrhagic events, a high rate of drug discontinuation, the need for frequent monitoring, and multiple food and drug interactions, warfarin has not been widely used recently to prevent ischemic events in patients with ACS.

The clinical trials with warfarin in ACS are probably not applicable to ACS patients managed by current strategies. During the 1990s, an early invasive approach for non-STsegment elevation acute coronary syndrome (NSTE ACS), primary angioplasty for ST segment elevation myocardial infarction (STEMI), coronary stents, and dual antiplatelet therapy were not widely used. The combination of dual antiplatelet therapy with warfarin is associated with a substantial increase in bleeding risk. In patients with atrial fibrillation, for example, the bleeding risk increases almost fourfold (RR 3.7; 95\% CI 2.9-4.8) when dual antiplatelet therapy is added to warfarin. ${ }^{11}$ Consequently, any potential net benefit of warfarin in ACS should take into account the increased bleeding risk from dual antiplatelet therapy in the context of an early invasive strategy.

The "2011 ACCF/AHA focused update of the Guidelines for the Management of Patients with Unstable Angina/ Non-ST-Elevation Myocardial Infarction (updating the 2007 guideline)," 12 indicates that warfarin with or without low-dose aspirin may be reasonable for patients at high risk of coronary artery disease and low risk of bleeding who do not require, or are intolerant of, clopidogrel (Level of evidence B).

\section{New, orally active, specific inhibitors of the coagulation pathway}

To overcome the limitations of warfarin, there has been a considerable amount of interest in developing agents that are: specific for individual coagulation factors blocking the synthesis and activation of thrombin; easier to use, with few dietary and drug interactions; and do not require routine coagulation monitoring. Within the last 10 years, more than five new oral anticoagulants that are specific inhibitors of the coagulation pathway (Figure 2) have become available. One of the earliest oral agents was ximelagatran, an antifactor IIa inhibitor, which was shown in the SPORTIF 3 trial to be effective for stroke prevention in patients with atrial fibrillation; ${ }^{13}$ however, this agent was withdrawn from use because of hepatic toxicity. Subsequently, the direct antithrombin inhibitor dabigatran etexilate and the anti-factor

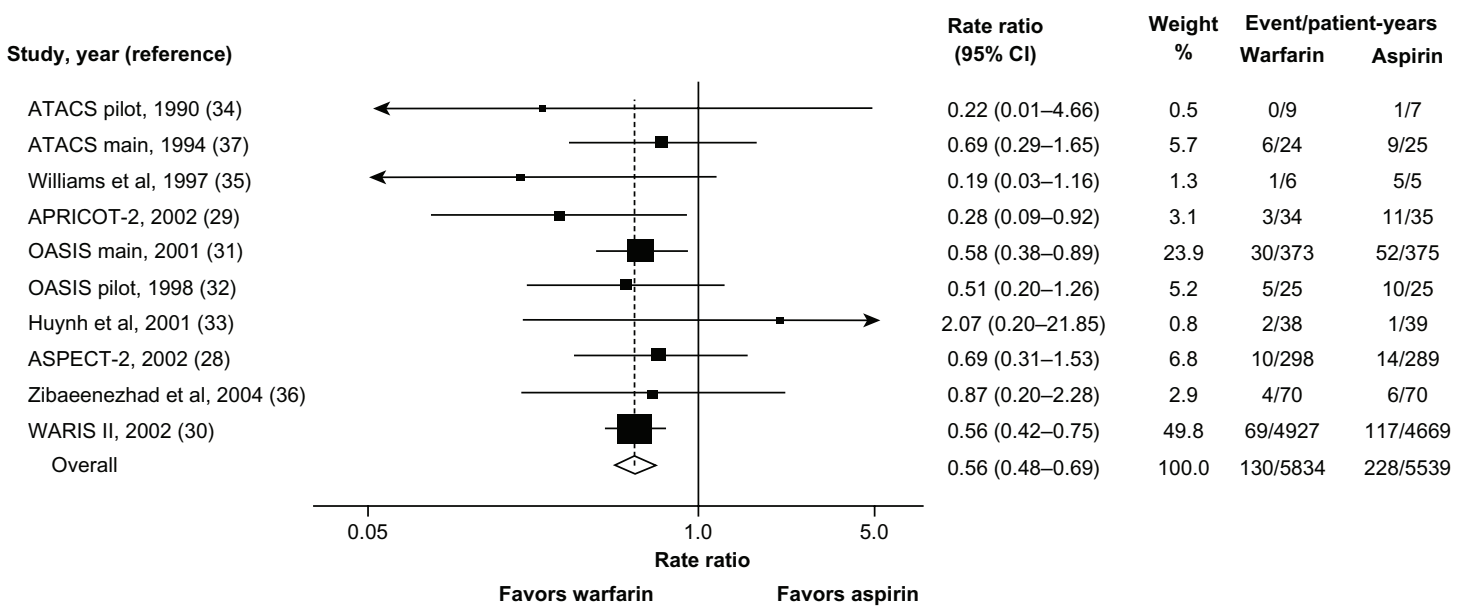

Figure I Benefit of warfarin added to acetylsalicylic acid in acute coronary syndromes for prevention of myocardial infarction.

Copyright $₫$ 2005. Annals of Internal Medicine. Reproduced from Rothberg MB, Celestin C, Fiore LD, Lawler E, Cook JR. Warfarin plus aspirin after myocardial infarction or the acute coronary syndrome: meta-analysis with estimates of risk and benefit. Ann Intern Med. 2005; 143(4):24I-250.10 
Xa inhibitors rivaroxaban, darexaban, and apixaban were investigated for the prevention of thromboembolism and recurrent ischemia in patients with recent ACS.

The properties of all five of these oral agents are shown in Table 1. Dabigatran is a direct inhibitor of thrombin. In contrast, both rivaroxaban and apixaban are direct selective competitive inhibitors of factor $\mathrm{Xa}$, therefore inhibit thrombin generation and fibrin formation. Dabigatran, administered twice daily [bid], is largely excreted renally, and should be avoided in patients with an estimated glomerular filtration rate (eGFR) of $<30 \mathrm{~mL} / \mathrm{min} .{ }^{14}$ Rivaroxaban was administered bid ( $2.5 \mathrm{mg}$ or $5 \mathrm{mg}$ ) in patients with ACS. This is in contrast to the much larger dose (15-20 mg once daily [od]), used for thromboembolism prevention in patients with atrial fibrillation. ${ }^{15}$ Approximately two-thirds of absorbed rivaroxaban is excreted renally, half as the unchanged agent and the other half as an inactive metabolite. ${ }^{16}$ Although rivaroxaban has a dual mode of excretion, there are no safety data to permit its use in patients with a glomerular filtration rate (GFR) of $<30 \mathrm{~mL} / \mathrm{min}$. Apixaban was administered at a dose of $5 \mathrm{mg}$ bid in the APPRAISE 2 Phase III trial ${ }^{17}$ in patients with ACS. Although apixaban is largely metabolized and depends only to a small degree on renal excretion, the dose was reduced in the APPRAISE 2 trial to $2.5 \mathrm{mg}$ bid in patients with an estimated creatinine clearance of $<40 \mathrm{~mL} / \mathrm{min}$. Darexaban is excreted by the kidneys and in the feces. In the RUBY-1 trial, patients received a total daily dose of $10-60 \mathrm{mg}$, either od or bid; patients with an eGFR of $<60 \mathrm{~mL} / \mathrm{min}$ were excluded.

\section{Clinical trials of specific orally active anticoagulants in ACS Ximelagatran}

The ESTEEM trial ${ }^{18}$ investigated the efficacy of ximelagatran (24-60 mg bid) in patients with a recent ACS receiving ASA, using either one of four doses or placebo. After 6 months' treatment, the primary end point of all-cause mortality, nonfatal MI, and severe recurrent ischemia was reduced $24 \%$ for the combined doses compared with placebo (hazard ratio [HR] 0.76 [95\% CI 0.59-0.98]; $P=0.036$ ). There was no indication of a dose response to ximelagatran. In all patients receiving ximelagatran, major bleeding was not significantly increased compared with placebo $(2.0 \%$ vs $1.0 \%$; not significant [ns]). Subsequently, as mentioned, ximelagatran was withdrawn after cases of fatal hepatotoxicity were observed during post-marketing surveillance following approval for atrial fibrillation.

\section{Dabigatran etexilate}

REDEEM was a Phase II double-blind placebo-controlled trial of 1862 patients with recent ACS who were receiving dual antiplatelet therapy. ${ }^{19}$ The study primarily examined the safety (primary end point of combined major and clinically relevant minor bleeding) of dabigatran at doses 50-150 mg bid for 6 months. Although there was a dose-dependent increase in major and clinically relevant minor bleeding (50 mg, HR 1.77 [95\% CI 0.70-4.50]; 75 mg, HR 2.17 [95\% CI 0.88-5.31]; $110 \mathrm{mg}$, HR 3.92 [95\% CI 1.72-8.95]; and $150 \mathrm{mg}$, HR 4.27 [95\% CI 1.86-9.81]), there was no demonstrable clinical benefit in the patients receiving dabigatran. Consequently, no Phase III trial with dabigatran in ACS has been undertaken.

\section{Apixaban}

The APPRAISE trial was a Phase II placebo-controlled dose-ranging safety study. ${ }^{20}$ Patients $(n=1715)$ with recent ACS were randomized to 6 months of placebo or to one of four doses of apixaban: $2.5 \mathrm{mg}$ bid, $10 \mathrm{mg} \mathrm{od}, 10 \mathrm{mg}$ bid, or $20 \mathrm{mg}$ od. There was a dose-dependent increase in major or clinically relevant non-major bleeding and a trend toward a reduction of ischemic events. APPRAISE $2,{ }^{21} \mathrm{a}$

Table I Properties of the specific oral anticoagulants

\begin{tabular}{|c|c|c|c|c|c|}
\hline & Ximelagatran & Dabigatran & Darexaban & Rivaroxaban & Apixaban \\
\hline Site of action & Ila (thrombin) & Ila (thrombin) & $\mathrm{Xa}$ & $\mathrm{Xa}$ & $\mathrm{Xa}$ \\
\hline $\mathrm{T} 1 / 2$ & & $12-14 \mathrm{~h}$ & $18-20 \mathrm{~h}$ & $9-13 \mathrm{~h}$ & $12 \mathrm{~h}$ \\
\hline Dose used for & $24-60 \mathrm{mg}$ bid & $50-150 \mathrm{mg}$ bid & Daily dose & ATLAS daily dose $5-20 \mathrm{mg}$, od or bid & APPRAISE. \\
\hline ACS trials & & & $10-60 \mathrm{mg}$, od or bid & ATLAS $22.5-5 \mathrm{mg}$ bid & APPRAISE $2.5 \mathrm{mg}$ bid \\
\hline Renal excretion & Mainly renal & $80 \%$ & Mainly renal & $66 \%$ (half as inactive metabolite) & $25 \%$ \\
\hline Phase II trials in ACS & ESTEEM $^{18}$ & RE-DEEM ${ }^{19}$ & RUBY-I ${ }^{22}$ & ATLAS ACS TIMI $46^{23}$ & APPRAISE $^{20}$ \\
\hline Phase III trials in ACS & None & None & None & ATLAS ACS 2-TIMI 5I ${ }^{17}$ & APPRAISE $2^{21}$ \\
\hline $\begin{array}{l}\text { Indications/ } \\
\text { proven benefit }\end{array}$ & Withdrawn & $\begin{array}{l}\text { AF, DVT } \\
\text { prophylaxis }\end{array}$ & Withdrawn & $\begin{array}{l}\text { AF, DVT prophylaxis, DVT treatment, } \\
\text { pulmonary embolism*, ACS* }\end{array}$ & AF, DVT prophylaxis \\
\hline
\end{tabular}

Note: *Indication not yet approved.

Abbreviations: ACS, acute coronary syndrome; AF, atrial fibrillation; DVT, deep vein thrombosis. 
Phase III randomized double-blind clinical trial, compared apixaban $5 \mathrm{mg}$ bid to placebo in 7392 ACS patients with two additional risk factors for recurrent ischemic events who were receiving standard antiplatelet therapy. The primary efficacy end point was CV death, MI, or ischemic stroke. The primary safety outcome was major bleeding, according to the thrombolysis in myocardial infarction (TIMI) definition. The trial was stopped prematurely after a median follow-up of 241 days due to an increase in major bleeding events with apixaban (TIMI major bleeding: HR 2.59, 95\% CI 1.50-4.46) without any significant reduction in recurrent ischemic events.

\section{Darexaban}

The RUBY-1 trial ${ }^{22}$ investigated the efficacy and safety of darexaban (10-60 $\mathrm{mg}$ od or bid for 6 days) in a placebocontrolled study of 1279 patients with recent ACS. The primary end point was combined major bleeding and clinically relevant non-major bleeding. Bleeding was increased in a dose-dependent manner, there was no indication of benefit at any dose of darexaban, and ischemic events were increased in patients receiving the higher doses. Darexaban has subsequently been withdrawn from further clinical development.

\section{Rivaroxaban}

The ATLAS ACS TIMI 46 trial $^{23}$ was a double-blind doseescalation Phase II trial of rivaroxaban at doses of 5 to $20 \mathrm{mg}$ daily in 3491 patients stabilized after a recent ACS. Patients were stratified according to the use of ASA or dual antiplatelet therapy with ASA plus a thienopyridine. The primary safety end point was clinically significant bleeding (TIMI major, TIMI minor, or requiring medical attention); the primary efficacy end point was death, MI, stroke, or severe recurrent ischemia requiring revascularization during 6 months. Bleeding was increased in a dose-dependent manner (5 mg, HR 2.21 [95\% CI 1.25-3.91]; $20 \mathrm{mg}$, HR 5.06 [95\% CI 3.45-7.42]). The primary efficacy end point of death, MI, stroke, or severe recurrent ischemia was lower in the rivaroxaban-treated patients, but the result did not achieve statistical significance (HR 0.79 [95\% CI 0.60-1.05]). The secondary efficacy end point of death, MI, or stroke was reduced 31\% (HR 0.69 [95\% CI 0.5-0.96]). As a result of the findings of the ATLAS ACS TIMI 46 trial, the ATLAS ACS 2-TIMI 52 trial $^{17}$ investigated low-dose rivaroxaban (2.5 and $5 \mathrm{mg}$ bid) in patients with recent ACS.

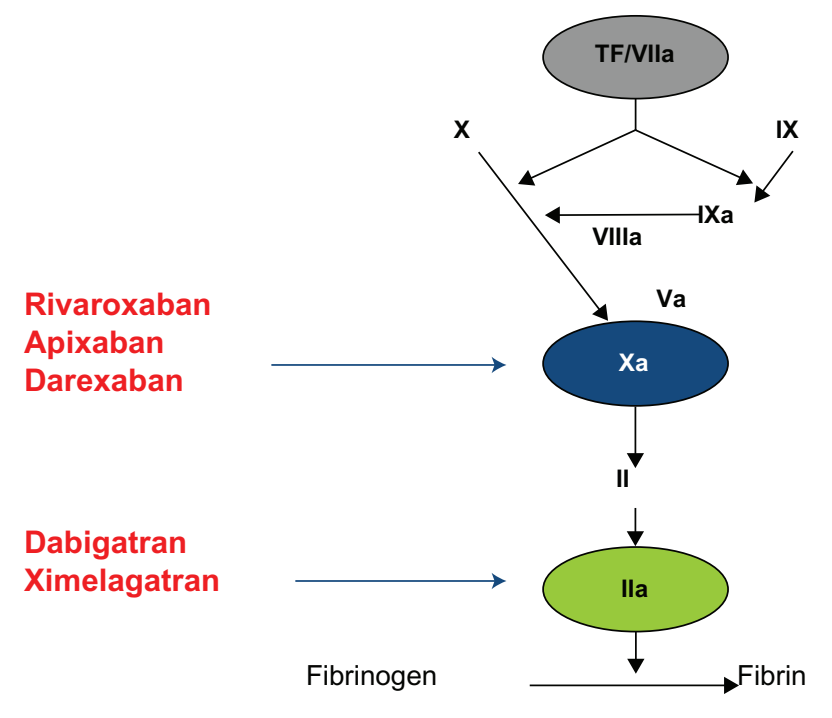

Figure 2 The sites of action of the new oral anticoagulants. Abbreviation: TF, tissue factor.

\section{The ATLAS ACS 2-TIMI 5 I trial}

The ATLAS ACS 2-TIMI 51 trial ${ }^{17}$ included 15,526 patients with recent ACS, 50.3\% of whom had STEMI, 25.6\% non-STEMI, and $24.0 \%$ unstable angina. The time to inclusion was 4.7 days (interquartile range 3.2-6 days) from onset of symptoms, when revascularization had been completed and intravenous anticoagulants discontinued. Patients aged under 55 years old also had to have diabetes or prior MI. Subjects were excluded if they were considered to have increased bleeding risk, such as if they were currently taking warfarin or had had gastrointestinal bleeding less than 1 year prior to the study, prior intracranial hemorrhage $(\mathrm{ICH})$, or prior stroke, if on ASA + thienopyridine. Patients were randomized to receive either rivaroxaban $5 \mathrm{mg}$ bid, $2.5 \mathrm{mg}$ bid, or placebo. Patients received all standard treatments including ASA with or without a thienopyridine (clopidogrel or ticlopidine). The mean treatment period was 13.1 months. Premature discontinuation of treatment with the $5 \mathrm{mg}$ bid dose was $29.4 \%, 26.9 \%$ with the $2.5 \mathrm{mg}$ bid dose, and $26.4 \%$ with placebo.

The baseline characteristics of the three treatment groups were well balanced, with no significant differences. The mean age was 61.8 years old, $75 \%$ were male, and $27 \%$ had had a prior MI. ASA was taken by $99 \%$ and a thienopyridine (clopidogrel, but not prasugrel) by $93 \%$.

\section{Efficacy outcomes}

Rivaroxaban reduced the primary combined efficacy end point (CV death, MI, or stroke) from $10.7 \%$ to $8.9 \%$ (HR 


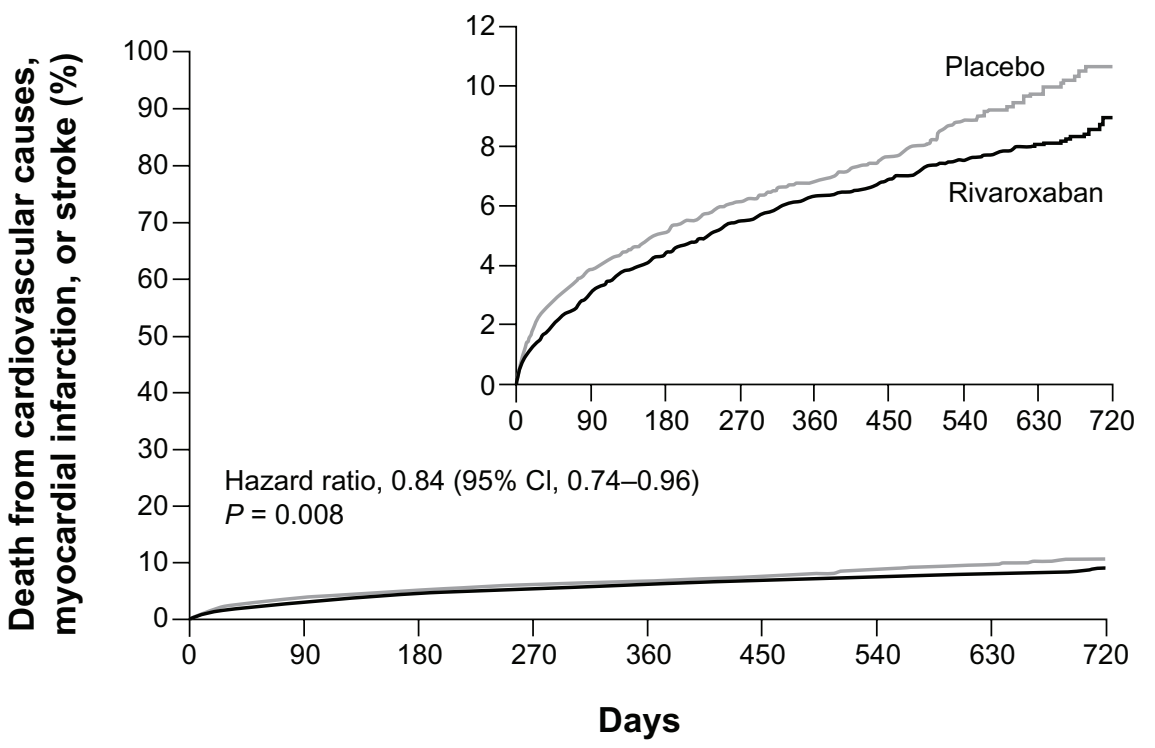

\section{No at risk Rivaroxaban Placebo}

$\begin{array}{ccccccccc}10,229 & 8817 & 7797 & 6324 & 5137 & 3967 & 2830 & 1747 & 831 \\ 5,113 & 4437 & 3974 & 3253 & 2664 & 2059 & 1460 & 878 & 421\end{array}$

Figure 3 Time to primary end point of cardiovascular death, myocardial infarction, or stroke for patients receiving either rivaroxaban or placebo. From Mega JL, Braunwald E, Wiviott SD, et al; ATLAS ACS 2-TIMI 5I Investigators. Rivaroxaban in patients with a recent acute coronary syndrome. N Engl J Med. 2012;366(I):9-19. Copyright@ 2012 Massachusetts Medical Society. Reprinted with permission from Massachusetts Medical Society. ${ }^{17}$

Abbreviation: $\mathrm{Cl}$, confidence interval.

0.84 [95\% CI 0.74-0.96]) (Figure 3). CV mortality (HR 0.80 [95\% CI 0.65-0.99]), all-cause mortality (HR 0.81 [95\% CI 0.66-1.0]), and recurrent MI (HR 0.85 [95\% CI 0.72-1.00]) were individually reduced by rivaroxaban. Stent thrombosis was significantly reduced by rivaroxaban $(2.3 \%$ vs $2.9 \%$ HR 0.69 [95\% CI 0.51-0.93]). Both doses of rivaroxaban reduced the primary end point $(2.5 \mathrm{mg}$ bid, HR 0.84 [95\% CI 0.72-0.97]; $5 \mathrm{mg}$ bid HR 0.85 [95\% CI 0.73-0.98]) by similar magnitudes. The $2.5 \mathrm{mg}$ bid dose significantly reduced $\mathrm{CV}$ and all-cause mortality whereas the $5 \mathrm{mg}$ bid dose did not appear to reduce mortality but did reduce recurrent MI. However, comparisons of outcomes between the doses should be interpreted with caution, as the study was not adequately powered to show any differences.

Both MI and CV death (Figure 4) and stent thrombosis, but not stroke, were significantly reduced by rivaroxaban treatment. There was consistent benefit over a wide range of subgroups, including patients receiving dual antiplatelet therapy and those with renal dysfunction (Table 2).

\section{Safety outcomes}

The bleeding event rates in the ATLAS ACS 2-TIMI 51 trial are shown in Table 3. TIMI major bleeding unrelated to coronary artery bypass graft surgery was increased by rivaroxaban
(2.1\% vs $0.6 \%$ HR 3.96 [95\% CI 2.46-6.38]). In addition, there were significant increases in TIMI minor bleeding, TIMI bleeding requiring medical attention, and $\mathrm{ICH}$. There was a trend to increased TIMI major bleeding for patients receiving rivaroxaban $5 \mathrm{mg}$ compared with $2.5 \mathrm{mg}(2.4 \%$ vs $1.8 \%, P=0.12$ ). However, the higher dose was associated with more TIMI minor bleeding $(1.6 \%$ vs $0.9 \%, P=0.046)$,

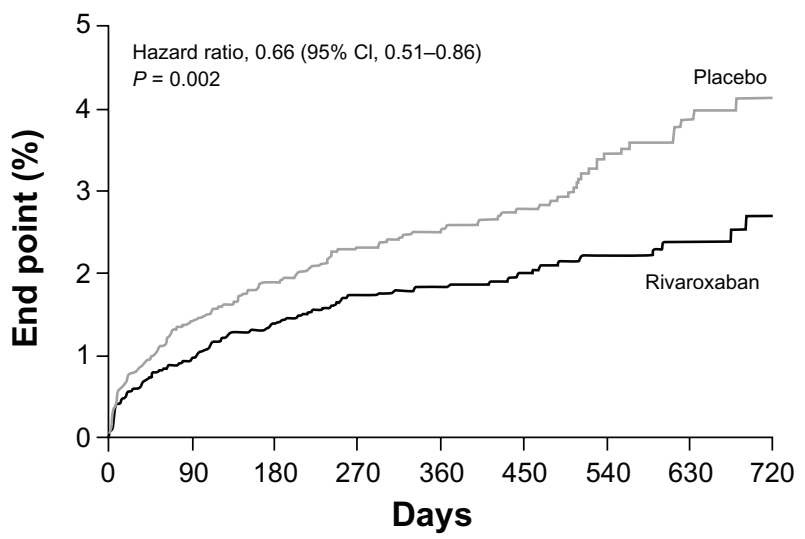

Figure 4 The ATLAS ACS 2-TIMI 5 I clinical trial: affect of rivaroxaban 2.5 mg twice daily on cardiovascular mortality.

From Mega JL, Braunwald E, Wiviott SD, et al; ATLAS ACS 2-TIMI 5 I Investigators. Rivaroxaban in patients with a recent acute coronary syndrome. $N$ Engl J Med. 2012;366(I):9-19. Copyright $\bigodot 2012$ Massachusetts Medical Society. Reprinted with permission from Massachusetts Medical Society. ${ }^{17}$ 
Table 2 Subgroup outcomes in the ATLAS ACS 2-TIMI 5 I clinical trial

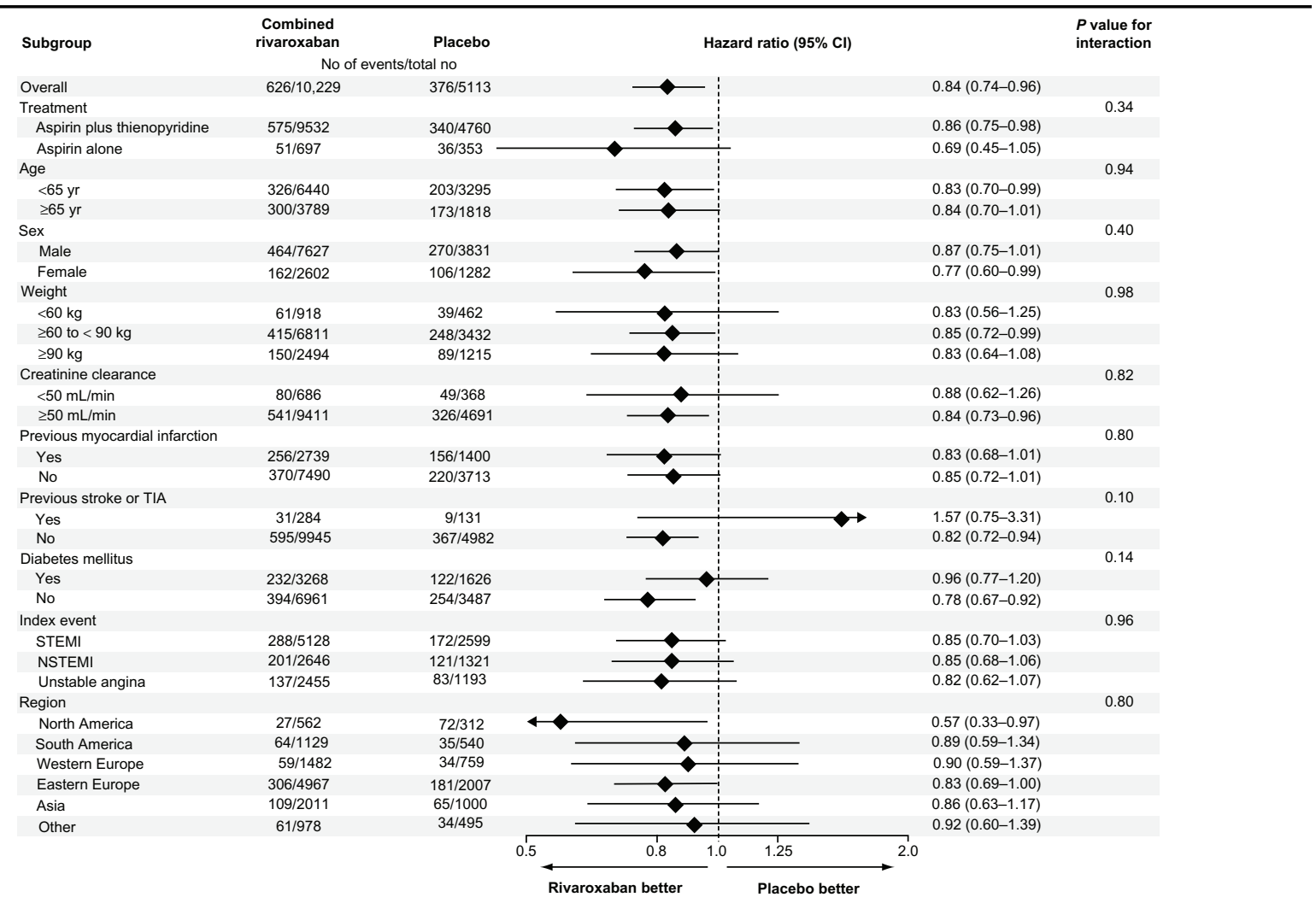

Note: From Mega JL, Braunwald E, Wiviott SD, et al; ATLAS ACS 2-TIMI 5 I Investigators. Rivaroxaban in patients with a recent acute coronary syndrome. N Engl J Med. 2012;366(I):9-19. Copyright@ 2012 Massachusetts Medical Society. Reprinted with permission from Massachusetts Medical Society. ${ }^{17}$

Abbreviations: $\mathrm{Cl}$, confidence interval; NSTEMI, non-ST segment elevation myocardial infarction; STEMI, ST segment elevation myocardial infarction; TIA, transient ischemic attack.

TIMI bleeding requiring medical attention $(16.2 \%$ vs $12.9 \%$, $P<0.001)$, and fatal bleeding $(0.4 \%$ vs $0.1 \%, P=0.04)$. Fatal bleeding was not increased in the group receiving $2.5 \mathrm{mg}$ bid compared with placebo. There were no significant interactions for the multiple subgroups examined. Increased bleeding with rivaroxaban was similar in older individuals, women, with renal dysfunction, and with low body weight. However, the number of high-risk individuals was small $(9 \%$ aged $>75$ years old, $25 \%$ female, and $25 \%$ reduced renal function) and confidence of the safety of rivaroxaban in these populations is limited. The impact of dual vs single antiplatelet therapy on bleeding is uncertain, as almost all (93\%) were taking ASA and a thienopyridine, and only a very small number were taking ASA alone.

Table 3 Safety outcomes for rivaroxaban $(2.5 \mathrm{mg}, 5 \mathrm{mg}$, and combined data) compared with placebo in the ATLAS ACS 2-TIMI $5 \mathrm{I}$ clinical trial

\begin{tabular}{|c|c|c|c|c|}
\hline \multirow[t]{2}{*}{ End point } & \multicolumn{3}{|l|}{ Rivaroxaban } & \multirow{2}{*}{$\begin{array}{l}\text { Placebo } \\
(N=5|| 3)\end{array}$} \\
\hline & $\begin{array}{l}2.5 \mathrm{mg} \text { twice daily } \\
(\mathrm{N}=5 \mid \mathrm{I})\end{array}$ & $\begin{array}{l}5 \mathrm{mg} \text { twice daily } \\
(\mathrm{N}=5|| 5)\end{array}$ & $\begin{array}{l}\text { Combined } \\
(\mathrm{N}=10,229)\end{array}$ & \\
\hline TIMI major bleeding not associated with CABG & $65(1.8)$ & $82(2.4)^{* *}$ & $147(2.1)^{* *}$ & $19(0.6)$ \\
\hline TIMI minor bleeding & $32(0.9)$ & $49(1.6)$ & $81(1.3)^{* *}$ & $20(0.5)$ \\
\hline TIMI bleeding requiring medical attention & $492(12.9)$ & $637(16.2)^{* *}$ & $1129(14.5)^{* *}$ & $282(7.5)$ \\
\hline Intracranial hemorrhage & $14(0.4)$ & $18(0.7)^{\dagger}$ & $32(0.6)^{*}$ & $5(0.2)$ \\
\hline Fatal bleeding & $6(0.1)$ & $15(0.4)$ & $21(0.3)$ & $9(0.2)$ \\
\hline
\end{tabular}

Notes: $* P \leq 0.005 ; * * P \leq 0.001 ;{ }^{\dagger} P \leq 0.04$. Figures in parentheses indicate percentages.

From Mega JL, Braunwald E, Wiviott SD, et al; ATLAS ACS 2-TIMI 5 I Investigators. Rivaroxaban in patients with a recent acute coronary syndrome. N Engl J Med. 2012;366(I):9-19. Copyright@ 2012 Massachusetts Medical Society. Reprinted with permission from Massachusetts Medical Society. ${ }^{17}$

Abbreviations: CABG, coronary artery bypass graft; TIMI, thrombolysis in myocardial infarction. 


\section{Comments on the ATLAS ACS 2-TIMI 5 I results}

In the ATLAS study, rivaroxaban was shown to reduce the combined end point of CV death, MI, and stroke by $16 \%$. Over the mean 13.1 months duration of the study, the incidence of the combined end point was reduced from $10.7 \%$ to $8.9 \%$. Consequently, 56 patients would require treatment with rivaroxaban to prevent one major $\mathrm{CV}$ event. Both $\mathrm{CV}$ and all-cause mortality were reduced by rivaroxaban $2.5 \mathrm{mg}$ bid and, to prevent one death, 63 patients would require treatment. The safety implications of treatment are that for every 67 patients treated with rivaroxaban, one will sustain a TIMI major bleed. Bleeding requiring medical attention was much more frequent, with one bleed for every 14 patients treated. ICH occurred at a rate of one patient in 250 treated with rivaroxaban, yet those patients on rivaroxaban suffering $\mathrm{ICH}$ had lower mortality and appeared to have less disability than when ICH occurred in the group receiving placebo.

ATLAS ACS 2-TIMI 51 is the first study to have shown that the addition of an anticoagulant to dual antiplatelet therapy reduces mortality. As recurrent MI and stroke were not reduced by rivaroxaban $2.5 \mathrm{mg}$ bid, the mechanism of the reduction of mortality is uncertain. Unwitnessed sudden death occurred more frequently in the placebo group than in the rivaroxaban $2.5 \mathrm{mg}$ bid group (81 vs 55 events). ${ }^{24}$ As $70 \%$ of sudden deaths after an ACS have a thrombotic basis, it is likely that rivaroxaban prevented sudden death by reducing thrombotic coronary occlusion. ${ }^{25}$

The US Food and Drug Administration (FDA) review in May $2012^{26}$ concluded that the ATLAS ACS 2-TIMI 51 trial had $11 \%-13 \%$ of patients with missing follow-up data. Differential event rates in the patients that dropped out and are part of the missing data may have influenced the outcome of the trial. Of the 1294 cases with missing data, a further attempt to ascertain outcomes was successful for only 183 subjects, of whom 177 were alive. The FDA analysis showed that bleeding rates were higher in patients with incomplete follow-up. It is known that in the trial, death and major adverse cardiac effect rates were higher when there was bleeding. The FDA presentation suggested the end-point differences between those patients receiving treatment and those receiving placebo were related to the higher bleeding rates in the patients with incomplete follow-up (even when incomplete ascertainment of bleeding is ignored). However, it would be expected that the bleeding rates in the rivaroxaban-treated patients with incomplete follow-up would be greater than for patients receiving placebo. This would tend to prejudice the study against rather than in favor of rivaroxaban. The FDA also noted that there was inaccurate reporting of mortality, with more errors in the treatment arm. The FDA reviewer concluded that as a high proportion of patients' vital statuses were undetermined, the claimed mortality rates are not reliable. The trial investigators' responses to these claims are awaited.

\section{The role for rivaroxaban in the management of ACS}

The older warfarin trials indicated that an antithrombotic agent could reduce recurrent ischemic events when administered in addition to ASA. However, increased bleeding and the difficulties in maintaining a stable and reliable degree of anticoagulation with warfarin did not lead to significant uptake of warfarin treatment for ACS in North America. Furthermore, with the current use of dual antiplatelet therapy in most patients with ACS, it is likely that bleeding rates would be much greater than reported in the original warfarin trials using ASA alone. The new specific coagulation pathway inhibitors offer the prospect of more controlled anticoagulation in an era of increased antiplatelet inhibition. Unfortunately, clinical trials in ACS with ximelagatran, dabigatran, apixaban, and darexaban have failed to show any benefit. Only the ATLAS ACS 2-TIMI 51 trial has shown rivaroxaban to reduce ischemic events including mortality, albeit at the cost of increased bleeding.

Since the ATLAS 2 study was performed, two potent antiplatelet agents, prasugrel and ticagrelor, have been introduced for the management of ACS. Both agents have shown improved outcomes (including a reduction of $\mathrm{CV}$ mortality for patients receiving ticagrelor) compared with the current standard of clopidogrel. ${ }^{2,27}$ Yet, there is no safety data for the combined use of rivaroxaban with either prasugrel or ticagrelor. As both the new antiplatelet agents increased nonsurgical bleeding, adding rivaroxaban to either agent cannot be recommended. Hence, there are now two new competing strategies to improve outcomes after ACS: (1) to use one of the new antiplatelet agents, ticagrelor or prasugrel, rather than clopidogrel or (2) to add rivaroxaban to clopidogrel. Comparisons of the clinical trials for the antiplatelet agents with the ATLAS ACS 2-TIMI 51 study are of very limited value, given the different patient populations and the duration and onset of treatment. For example, in the PLATO and TRITON studies, ticagrelor or prasugrel was administered 
within 24-72 hours of symptom onset, more effectively reducing early recurrent ischemic events. In contrast, in the ATLAS ACS 2-TIMI 51 trial, rivaroxaban was initiated at a median 7 days after the ACS event.

\section{Rivaroxaban in the management of ACS patients}

As rivaroxaban reduces mortality, it is likely that the increased bleeding risk will be an acceptable hazard in some patients at high risk of recurrent ischemic events (eg, those with diabetes or medically managed patients with multivessel coronary disease, and those with atherosclerotic vascular disease in multiple territories) but with a low bleeding risk. It will be especially important to avoid the use of rivaroxaban in patients at a high bleeding risk. These would include elderly patients and those with a history of recent gastrointestinal bleeding and/or a history of stroke, transient ischemic attack, and, especially, ICH. Rivaroxaban is likely to be used in younger patients with no history of stroke/transient ischemic attack who are at high risk for recurrent events.

\section{Conclusion}

As more potent antithrombotic therapies are being used, it is becoming increasingly important to optimize the benefit/risk of treatment by assessing both the risk of recurrent ischemic events as well as the risk of major bleeding. Rivaroxaban provides a new strategy to potentially reduce residual ischemic risk after ACS, which will likely play an important role in personalized secondary prevention. However, prior to widely endorsing this new strategy, it will be important to await the ATLAS ACS 2-TIMI 51 investigators' response and updated analysis following the FDA review.

\section{Disclosure}

The author declares no conflicts of interest in this work.

\section{References}

1. Yusuf S, Zhao F, Mehta SR, Chrolavicius S, Tognoni G, Fox KK. Effects of clopidogrel in addition to aspirin in patients with acute coronary syndromes without ST-segment elevation. $N$ Engl J Med. 2001;345(7):494-502.

2. Wallentin L, Becker RC, Budaj A, et al. Ticagrelor versus clopidogrel in patients with acute coronary syndromes. $N$ Engl $J$ Med. 2009;361(11):1045-1057.

3. Merlini PA, Bauer KA, Oltrona L, et al. Persistent activation of coagulation mechanism in unstable angina and myocardial infarction. Circulation. 1994;90(1):61-68.

4. Cohen M, Demers C, Gurfinkel E, et al. A comparison of low-molecularweight heparin with unfractionated heparin for unstable coronary artery disease. Efficacy and Safety of Subcutaneous Enoxaparin in Non-Q-Wave Coronary Events Study Group. N Engl J Med. 1997;337(7):447-452.
5. Fifth Organization to Assess Strategies in Acute Ischemic Syndromes Investigators, Yusuf S, Mehta SR, et al. Comparison of fondaparinux and enoxaparin in acute coronary syndromes. $N$ Engl $\mathrm{J} \mathrm{Med}$. 2006;354(14):1464-1476.

6. Stone GW, McLaurin BT, Cox DA, et al; ACUITY Investigators. Bivalirudin for patients with acute coronary syndromes. $N$ Engl J Med. 2006;355(21):2203-2216.

7. Husted SE, Wallentin L, Lagerqvist B, Kontny F, Ståhle E, Swahn E. Benefits of extended treatment with dalteparin in patients with unstable coronary artery disease eligible for revascularization. Eur Heart J. 2002;23(15):1213-1218.

8. Hurlen M, Smith P, Arnesen H. Effects of warfarin, aspirin and the two combined, on mortality and thromboembolic morbidity after myocardial infarction. The WARIS-II (Warfarin-Aspirin Reinfarction Study) design. Scand Cardiovasc J. 2000;34(2):168-171.

9. Effects of long-term, moderate-intensity oral anticoagulation in addition to aspirin in unstable angina. The Organization to Assess Strategies for Ischemic Syndromes (OASIS) Investigators. $J$ Am Coll Cardiol. 2001;37(2):475-484.

10. Rothberg MB, Celestin C, Fiore LD, Lawler E, Cook JR. Warfarin plus aspirin after myocardial infarction or the acute coronary syndrome: meta-analysis with estimates of risk and benefit. Ann Intern Med. 2005;143(4):241-250.

11. Hansen ML, Sorensen R, Clausen MT, et al. Risk of bleeding with single, dual, or triple therapy with warfarin, aspirin, and clopidogrel in patients with atrial fibrillation. Arch Intern Med. 2010;170(16): 1433-1441.

12. Wright SA, Anderson JL, Adams CD, et al. 2011 ACCF/AHA focused update of the Guidelines for the Management of Patients with Unstable Angina/Non-ST-Elevation Myocardial Infarction (updating the 2007 guideline): a report of the American College of Cardiology Foundation/American Heart Association Task Force on Practice Guidelines developed in collaboration with the American College of Emergency Physicians, Society for Cardiovascular Angiography and Interventions, and Society of Thoracic Surgeons. J Am Coll Cardiol. 2011;57(19):1920-1959.

13. Olsson SB; Executive Steering Committee of the SPORTIF III Investigators. Stroke prevention with the oral direct thrombin inhibitor ximelagatran compared with warfarin in patients with non-valvular atrial fibrillation (SPORTIF III): randomised controlled trial. Lancet. 2003;362(9397):1691-1698.

14. Pradax product monograph. Boehringer Ingelheim Canada. January 27, 2012.

15. Patel MR, Mahaffey KW, Garg J, et al. Rivaroxaban versus warfarin in nonvalvular atrial fibrillation. N Engl J Med. 2011;365:883-891.

16. Weinz C, Schwarz T, Kubitza D, Mueck W, Lang D. Metabolism and excretion of rivaroxaban, an oral, direct factor Xa inhibitor, in rats, dogs, and humans. Drug Metab Dispos. 2009;37(5): 1056-1064.

17. Mega JL, Braunwald E, Wiviott SD, et al; ATLAS ACS 2-TIMI 51 Investigators. Rivaroxaban in patients with a recent acute coronary syndrome. N Engl J Med. 2012;366(1):9-19.

18. Wallentin L, Wilcox RG, Weaver WD, et al. Oral ximelagatran for secondary prophylaxis after myocardial infarction: the ESTEEM randomised controlled trial. Lancet. 2003;362(9386):789-797.

19. Oldgren J, Budaj A, Granger CB, et al; RE-DEEM Investigators. Dabigatran vs placebo in patients with acute coronary syndromes on dual antiplatelet therapy: a randomized, double-blind, phase II trial. Eur Heart J. 2011;32(22):2781-2789.

20. APPRAISE Steering Committee and Investigators, Alexander JH, Becker RC, et al. Apixaban, an oral, direct, selective factor Xa inhibitor, in combination with antiplatelet therapy after acute coronary syndrome: results of the Apixaban for Prevention of Acute Ischemic and Safety Events (APPRAISE) trial. Circulation. 2009;119(22):2877-2885.

21. Alexander JH, Lopes RD, James S, et al; APPRAISE-2 Investigators. Apixaban with antiplatelet therapy after acute coronary syndrome. N Engl J Med. 2011;365(8):699-708. 
22. Steg PG, Mehta SR, Jukema JW, et al; RUBY-1 Investigators. RUBY-1: a randomized, double-blind, placebo-controlled trial of the safety and tolerability of the novel oral factor Xa inhibitor darexaban (YM150) following acute coronary syndrome. Eur Heart J. 2011;32(20): 2541-2554.

23. Mega JL, Braunwald E, Mohanavelu S, et al; ATLAS ACS-TIMI 46 study group. Rivaroxaban versus placebo in patients with acute coronary syndromes (ATLAS ACS-TIMI 46): a randomised, doubleblind, phase II trial. Lancet. 2009;374(9683):29-38.

24. Janssen Research and Development. Rivaroxaban for Reducing the Risk of Cardiovascular Events (Cardiovascular Death, Myocardial Infarction and Stroke) After Acute Coronary Syndrome (ACS). Advisory committee briefing document JNJ-39039039; BAY 59-7939 (rivaroxaban). Raritan, NJ: Janssen Research and Development; April 24, 2012. Available from: http://www. fda.gov/downloads/AdvisoryCommittees/CommitteesMeetingMaterials/ Drugs/CardiovascularandRenalDrugsAdvisoryCommittee/UCM304757. pdf. Accessed June 14, 2012.

25. Davis MJ, Thomas A. Thrombosis and acute coronary artery lesions in sudden cardiac ischemic death. $N$ Engl J Med. 1984;310(18):1138-1140.

26. US Food and Drug Administration (FDA). FDA Briefing Document for the Cardiovascular and Renal Drugs Advisory Committee (CRDAC). NDA: 202439/S-002. Drug: Xarelto ${ }^{\circledR}$ (Rivaroxaban) oral tablets. Silver Spring, MD: FDA; May 23, 2012. Available from: http://www.fda.gov/ downloads/AdvisoryCommittees/CommitteesMeetingMaterials/Drugs/ CardiovascularandRenalDrugsAdvisoryCommittee/UCM304755.pdf. Accessed June 14, 2012.

27. Wiviott SD, Braunwald E, McCabe $\mathrm{CH}$, et al. Prasugrel versus clopidogrel in patients with acute coronary syndromes. $N$ Engl J Med. 2007;357(20):2001-2015.

28. van Es RF, Jonker JJ, Verheugt FW, Deckers JW, Grobbee DE. Aspirin and coumadin after acute coronary syndromes (the ASPECT-2 study): a randomized controlled trial. Lancet. 2002;360:109-113.

29. Brouwer MA, van den Bergh PJ, Aengevaeren WR, et al. Aspirin plus coumarin versus aspirin alone in the prevention of reocclusion after fibrinolysis for acute myocardial infarction: results of the Antithrombotics in the Prevention of Reocclusion In Coronary Thrombolysis (APRICOT)-2 Trial. Circulation. 2002;106:659-665.
30. Hurlen M, Abdelnoor M, Smith P, Erikssen J, Arnesen H. Warfarin, aspirin, or both after myocardial infarction. N Engl J Med. 2002;347: 969-974.

31. Effects of long-term, moderate-intensity oral anticoagulation in addition to aspirin in unstable angina. The Organization to Assess Strategies for Ischemic Syndromes (OASIS) Investigators. J Am Coll Cardiol. 2001;37:475-484.

32. Anand SS, Yusuf S, Pogue J, Weitz JI, Flather M. Long-term oral anticoagulant therapy in patients with unstable angina or suspected non-Q-wave myocardial infarction: organization to assess strategies for ischemic syndromes (OASIS) pilot study results. Circulation. 1998;98:1064-1070.

33. Huynh T, Théroux P, Bogaty P, Nasmith J, Solymoss S. Aspirin, warfarin, or the combination for secondary prevention of coronary events in patients with acute coronary syndromes and prior coronary artery bypass surgery. Circulation. 2001;103:3069-3074.

34. Cohen M, Adams PC, Hawkins L, Bach M, Fuster V. Usefulness of antithrombotic therapy in resting angina pectoris or non-Q-wave myocardial infarction in preventing death and myocardial infarction (a pilot study from the Antithrombotic Therapy in Acute Coronary Syndromes Study Group). Am J Cardiol. 1990;66:1287-1292.

35. Williams MJ, Morison IM, Parker JH, Stewart RA. Progression of the culprit lesion in unstable coronary artery disease with warfarin and aspirin versus aspirin alone: preliminary study. J Am Coll Cardiol. 1997;30:364-369.

36. Zibaeenezhad MJ, Mowla A, Sorbi MH. Warfarin and aspirin versus aspirin alone in patients with acute myocardial infarction: a pilot study. Angiology. 2004;55:17-20.

37. Cohen M, Adams PC, Parry G, et al. Combination antithrombotic therapy in unstable rest angina and non-Q-wave infarction in nonprior aspirin users. Primary end points analysis from the ATACS trial. Antithrombotic Therapy in Acute Coronary Syndromes Research Group. Circulation. 1994;89(1):81-88.
Drug Design, Development and Therapy

\section{Publish your work in this journal}

Drug Design, Development and Therapy is an international, peerreviewed open-access journal that spans the spectrum of drug design and development through to clinical applications. Clinical outcomes, patient safety, and programs for the development and effective, safe, and sustained use of medicines are a feature of the journal, which

\section{Dovepress}

has also been accepted for indexing on PubMed Central. The manuscript management system is completely online and includes a very quick and fair peer-review system, which is all easy to use. Visit http://www.dovepress.com/testimonials.php to read real quotes from published authors. 